\title{
Atrazine promotes RM1 prostate cancer cell proliferation by activating STAT3 signaling
}

\author{
KEBANG HU $^{1 *}$, YONG TIAN ${ }^{2 *}$, YANWEI DU ${ }^{3 *}$, LIANDI HUANG $^{2}$, JUNYU CHEN $^{2}$, \\ $\mathrm{NA} \mathrm{LI}^{3}$, WEI LIU ${ }^{4}, \mathrm{ZUOWEN} \mathrm{LIANG}^{1}$ and LIJING ZHAO ${ }^{2}$ \\ ${ }^{1}$ The First Hospital of Jilin University; ${ }^{2}$ College of Basic Medical Sciences, Jilin University, \\ Changchun, Jilin 130021; ${ }^{3}$ Changchun University of Chinese Medicine, Changchun, \\ Jilin 130117; Jilin Academy of Environmental Science, Jilin, P.R. China
}

Received December 21, 2015; Accepted February 17, 2016

DOI: 10.3892/ijo.2016.3433

\begin{abstract}
Atrazine, a widely used pesticide, is frequently detected in soil and surface water, which alarms epidemiologists and medical professionals because of its potential deleterious effects on health. Indeed, atrazine is a potent endocrine disruptor that increases aromatase expression in some human cancer cell lines. Both animal and human studies have suggested that atrazine is possibly carcinogenic, although discrepant results have been reported. In this study, RM1 cells were used to explore the atrazine effects on prostate cancer. Proliferation, migration and invasion of RM1 cells were assessed by colony formation, wound-healing and invasion assays, respectively, after in vitro exposure to atrazine. In addition, an RM1 cell xenograft model was generated to evaluate the effects of atrazine in vivo. To explore the molecular mechanisms, qRT-PCR, immunohistochemistry, and western blot analyses were employed to detect mRNA and protein levels of STAT3 signaling and cell cycle related proteins, including p53, p21, cyclin B1 and cyclin D1. Interestingly, RM1 cell proliferation was increased after treatment with atrazine, concomitantly with STAT3 signaling activation. These results suggest that atrazine promotes RM1 cell growth in vitro and in vivo by activating STAT3 signaling.
\end{abstract}

\section{Introduction}

The herbicide atrazine (2-chloro-4-(ethylamino)-6(isopropylamino)-S-triazine; ATR) is a pesticide widely used in agriculture worldwide to control broadleaf weeds in crops

Correspondence to: Dr Lijing Zhao, College of Basic Medical Sciences, Jilin University, Changchun, Jilin 130021, P.R. China E-mail: zhao_lj@jlu.edu.cn

Dr Zuowen Liang, The First Hospital of Jilin University, Changchun, Jilin 130021, P.R. China

E-mail: liangzw@jlu.edu.cn

*Contributed equally

Key words: apoptosis, atrazine, proliferation, prostate cancer, Stat 3 such as corns, sugarcane, and sorghum (1). In the United States alone, the annual use of ATR is $\sim 65-80$ million pounds (2). Gerecke et al demonstrated that atrazine is the most frequently detected pesticide in soil and surface water even in urban areas (3). In China, atrazine has been reported in Guanting reservoir and Taihu Lake (4,5). Previous in vivo toxicological studies mostly focused on the effects of atrazine on endocrine and reproductive systems, demonstrating that it overtly disrupts the hypothalamic control of pituitary-ovarian function, which results in altered pituitary prolactin and luteinizing hormone secretion (6-8). In addition, atrazine is associated with global DNA hypomethylation (9), and induces apoptosis of splenocytes (10). In terms of relevance between atrazine and tumors, Boffetta et al insisted that ATR has no causal association with tumor development and should be considered an agent unlikely to pose a cancer risk to humans (11); however, Van Leeuwen et al reported that ATR contamination levels are positively associated with stomach cancer incidence (12). It should be noted that the above views are mostly based on epidemiological studies.

In this study, the RM1 prostate cancer cell line was used to study the effects of atrazine in vitro, and a subcutaneous tumor model was established in mice to explore the impacts of atrazine on tumors in vivo as well as the underlying mechanisms.

\section{Materials and methods}

Cell lines and reagents. RM1 cells were obtained from the Shanghai Institute of Cell Biology, Chinese Academy of Sciences (Shanghai, China). They were cultured in IMDM supplemented with $10 \%$ fetal bovine serum (Gibco BRL, Gaithersburg, MD, USA), in a humidified environment with $5 \% \mathrm{CO}_{2}$ at $37^{\circ} \mathrm{C}$. Atrazine (99\% purity), SDS, TEMED, Acrylamide, N, N-Dimethyl-bis-acrylamide, DTT and PMSF were obtained from Sigma Chemical Co. (USA). ATR stock solutions $\left(10^{-2} \mathrm{~mol} / \mathrm{l}\right)$ were prepared in corn oil (13), and kept at $4^{\circ} \mathrm{C}$ for a maximum of 1 week. Anti-Grim-19, Stat3, MMP9, MMP2, VEGF, PCNA, P53, c-myc, Cyclin B1, Cyclin D1, Bcl-2, Bax, and Caspase-3 primary antibodies, as well as secondary antibodies were acquired from Proteintech Group (USA). Pierce ECL Plus kit was purchased from Thermo Fisher Scientific Inc. (USA). 
Tumor xenograft models. C57BL6 mice (18-22 g) were purchased from the Beijing Institute for Experimental Animals, and housed at constant room temperature $\left(23 \pm 1^{\circ} \mathrm{C}\right)$ and relative humidity $(50 \%)$ under a 12 -h light/dark cycle, with food and water ad libitum. Mice were transplanted subcutaneously with $2 \times 10^{6}$ RM1 cells on the right flank and randomly divided into three groups for 15 daily oral treatments with 0,20 and $100 \mathrm{mg} / \mathrm{kg}$ atrazine, respectively (14). The animals were sacrificed by ether and transplanted tumors were removed, fixed in $10 \%$ formalin or stored at $-80^{\circ} \mathrm{C}$. The animal experiments were conducted following internationally recognized guidelines, and approved by the Animal Research Committee of Norman Bethune College of Medicine, Jilin University.

MTT assay. The effects of atrazine on RM1 cell proliferation in vitro was measured using MTT (Sigma-Aldrich, St. Louis, MO, USA). Briefly, RM1 cells were seeded in 96-well plates and incubated at $37^{\circ} \mathrm{C}$ in the presence of variable concentrations of atrazine, including $0 \mu \mathrm{M}$ (control), 0.1 and $0.01 \mu \mathrm{M}$ for $24 \mathrm{~h}$. Then, $10 \mu \mathrm{l}$ of $5 \mathrm{mg} / \mathrm{ml}$ MTT in PBS was added to each well then incubated for $4 \mathrm{~h}$ at $37^{\circ} \mathrm{C}$. After careful removal of the culture medium, the formazan crystals were solubilized in $100 \mu 1$ DMSO (Sigma) with shaking for $15 \mathrm{~min}$. Absorption was measured at $570 \mathrm{~nm}$ on a microplate reader (Bio-Rad). Each assay was performed nine times and results are expressed as mean $\pm \mathrm{SE}(15)$.

Colony formation assay. Cells were seeded in 6-well culture plates at $10^{4}$ cells/well. After 10 days of incubation, they were stained with Giemsa. Colonies with $>50$ cells were counted, and colony formation rate acquired as the number of colonies formed to that of seeded cells (16).

Invasion assay. Cell invasion was measured using a Matrigelcoated film insert ( $8-\mu \mathrm{m}$ pore size) fitting into 24 -well invasion chambers (Millipore, GE, USA). A total of $5 \times 10^{4}$ cells were suspended in $200 \mu \mathrm{l}$ IMDM, and added into the upper compartment of the invasion chamber; after the medium was removed, cells on the lower surface of the filter were stained and counted under a microscope (Olympus) at a magnification of x 200 (17). The cells in the lower chamber were incubated at $37^{\circ} \mathrm{C}$ for another $24 \mathrm{~h}$; MTT was added to a final concentration of $1 \mathrm{mM}$. After $4 \mathrm{~h}$, formazan crystals were dissolved by addition of DMSO. Optical densities were measured on a microplate reader at $490 \mathrm{~nm}$. Data are mean \pm standard error from at least 3 independent experiments.

In vitro wound-healing assay. Cells were cultured in a 6 -well plate. Confluent monolayers were scratched with a $200-\mu 1$ pipette tip to generate a wound. The monolayer was then washed twice with PBS to remove the detached cells, supplemented with different doses of atrazine, and incubated for $48 \mathrm{~h}$ at $37^{\circ} \mathrm{C}$. Images were captured on a Nikon Eclipse TS-100 microscope fitted with a digital camera to monitor the cell movement into the wounded area. All micrographs were taken at the same time and magnification (18).

Real-time quantitative PCR. Gene expression levels of Stat3 and its downstream genes were determined using real-time quantitative PCR (qPCR). Cells were collected after $48 \mathrm{~h}$, and
Table I. Primer sets used for real-time qRT-PCR.

\begin{tabular}{|c|c|}
\hline Gene & Primers \\
\hline Stat3 & $\begin{array}{l}\text { 5'-TTGCCAGTTGTGGTGATC-3' } \\
\text { 5'-AGAACCCAGAAGGAGAAGC-3' }\end{array}$ \\
\hline Grim19 & $\begin{array}{l}\text { 5'-GTGGTGTAGGCACTGCAGGTTC-3' } \\
\text { 5'-GAACTTCGTCGATCGACCTCGA-3' }\end{array}$ \\
\hline Bax & $\begin{array}{l}\text { 5-'AGGGTTTCATCCAGGATCGAGC-3' } \\
\text { 5-'AGGCGGTGAGGACTCCAGCC-3' }\end{array}$ \\
\hline Bcl-2 & $\begin{array}{l}\text { 5'-ACTTGACAGAAGATCATGCC-3' } \\
\text { 5'-GGTTATCATACCCTGTTCTC-3' }\end{array}$ \\
\hline Caspase-3 & $\begin{array}{l}\text { 5'-TGGACTGTGGCATTGAGAC-3' } \\
\text { 5'-AGGAATAGTAACCAGGTGCTG-3' }\end{array}$ \\
\hline VEGF & $\begin{array}{l}\text { 5'-AGTCCCATGAAGTGATCAAGTTC-3' } \\
\text { 5'-ATCCGCATGATCTGCATGG-3' }\end{array}$ \\
\hline$c-m y c$ & $\begin{array}{l}\text { 5'-AGTTGGACAGTGGCAGGG-3' } \\
\text { 5'-ACAGGATGTAGGCGGTGG-3' }\end{array}$ \\
\hline p53 & $\begin{array}{l}\text { 5'-GGCCATCTACAAGCAGTCACAG-3' } \\
\text { 5'-AGCAAATCTACAAGCAGTCACAG-3' }\end{array}$ \\
\hline p21 & $\begin{array}{l}\text { 5'-TAGCAGCGGAACAAGGAG-3' } \\
\text { 5'-AAACGGGAACCAGGACAC-3' }\end{array}$ \\
\hline Cyclin D1 & $\begin{array}{l}\text { 5'-CGCCTTCCGTTTCTTACTTCA-3' } \\
\text { 5'-AACTTCTCGGCAGTCAGGGGA-3' }\end{array}$ \\
\hline MMP2 & $\begin{array}{l}\text { 5'-GGAAGCATCAAATCGGACTG-3' } \\
\text { 5'-CACCCTCTTAAATCTGAAATCACC-3 }\end{array}$ \\
\hline MMP9 & $\begin{array}{l}\text { 5'-CCCACTTACTTTGGAAACG-3' } \\
\text { 5'-GAAGATGAATGGAAATACGC-3' }\end{array}$ \\
\hline Cyclin B1 & $\begin{array}{l}\text { 5'-GCGTGTGCCTGTGACAGTTA-3' } \\
\text { 5'-CCTAGCGTTTTTGCTTCCCTT-3' }\end{array}$ \\
\hline$\beta$-actin & $\begin{array}{l}\text { 5'-ATATCGCTGCGCTGGTCGTC-3' } \\
\text { 5'-AGGATGGCGTGAGGGAGAGC-3' }\end{array}$ \\
\hline
\end{tabular}

total RNA was extracted using TRIzol reagent (Invitrogen, Carlsbad, CA, USA). Reverse transcription was performed with $2 \mu \mathrm{g}$ total RNA treated with DNAse I, using a commercially available RT-PCR kit (Promega, Madison, WI, USA) according to the manufacturer's instructions. Quantitative-PCR primers are shown in Table I. Each reaction $(25 \mu \mathrm{l})$ was carried out under the following cycling conditions: initialization for $10 \mathrm{~min}$ at $95^{\circ} \mathrm{C} ; 40$ cycles of amplification, with $15 \mathrm{sec}$ at $95^{\circ} \mathrm{C}$ (denaturation), and $1 \mathrm{~min}$ at $60^{\circ} \mathrm{C}$ (annealing and elongation). A standard curve was plotted for each primer probe by using a serial dilution of pooled cDNA from cells. All standards and samples were assessed in triplicate. Quantification was carried out by normalizing gene expression levels to total cDNA amounts obtained for the ubiquitously expressed $\beta$-actin as a standard (19).

Apoptosis and cell cycle assessment. RM1 cells $\left(1 \times 10^{6}\right)$ were treated with the indicated drugs for up to $48 \mathrm{~h}$, collected, and resuspended in $100 \mu \mathrm{l}$ PBS. Then, $5 \mu \mathrm{l}$ PI (Beckman Coulter, Fullerton, CA, USA) was added for $30 \mathrm{~min}$ at room temperature in the dark. The cells were assessed by flow cytometry to measure apoptosis rates on an Epics-XL-MCL flow cytometer 

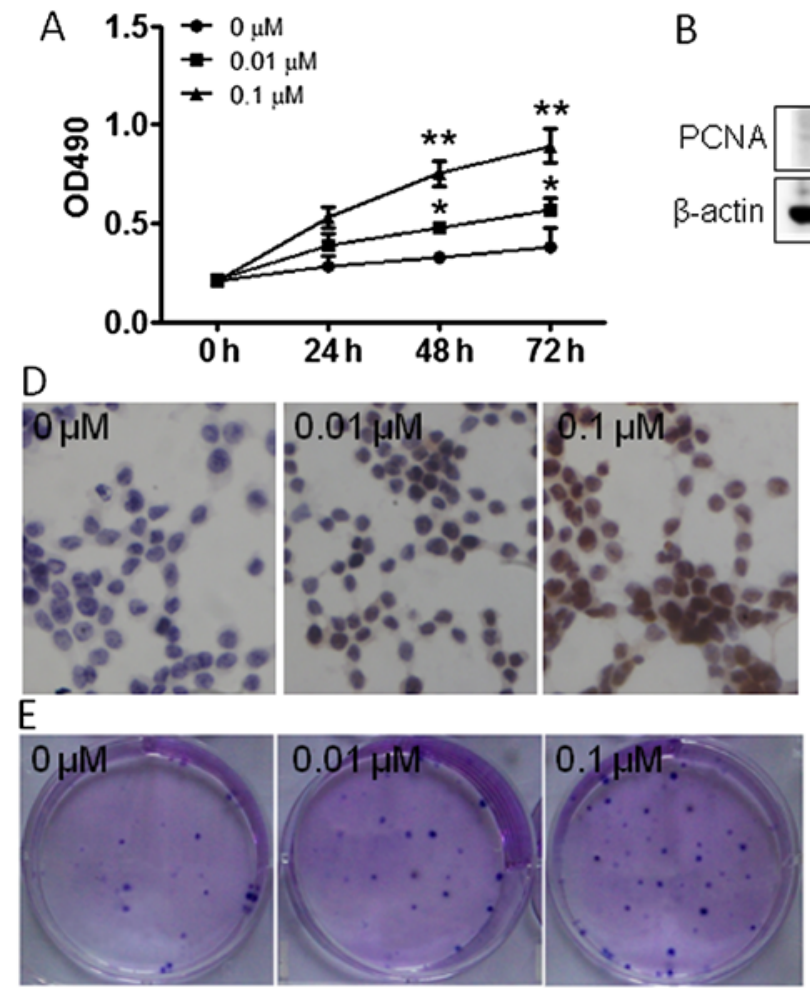

B
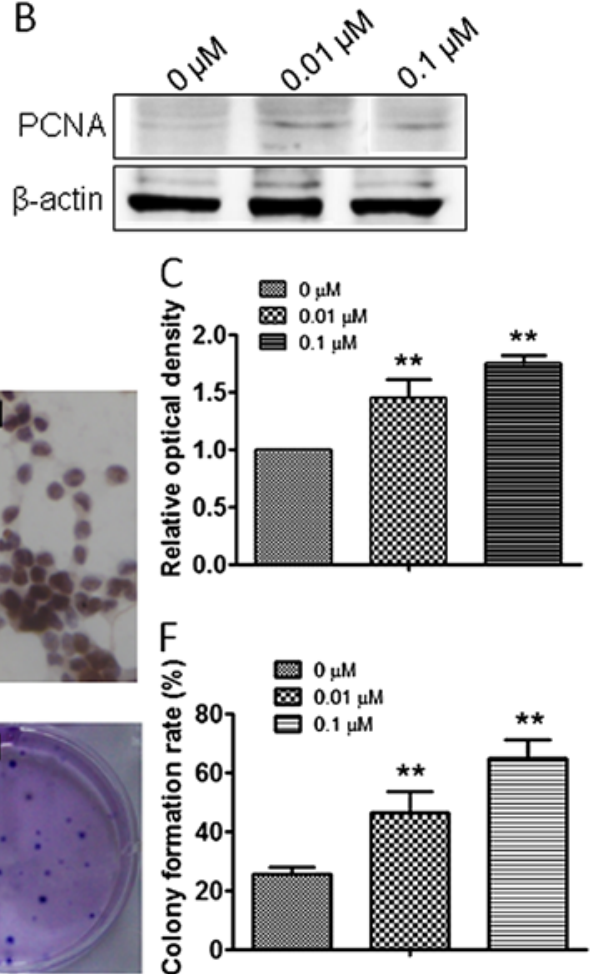

Figure 1. Atrazine promotes the proliferation of RM1 cells in vitro. (A) Growth effects were evaluated with MTT assay for RM1 cells treated with atrazine; data are mean \pm standard error from at least 3 independent experiments. (B) Western blot analysis of the PCNA protein in RM1 cells treated with atrazine. (C) Quantitation of PCNA protein levels from three separate experiments. Columns, mean; bars, SE (** $\mathrm{P}<0.01$ versus control). (D) PCNA was evaluated by immunohistochemical analysis in vitro. (E and F) Colony formation images and histograms.

(Beckman Coulter). Cell cycle distribution was analyzed by measuring the DNA fragments stained with PI, as described by the manufacturer. RM1 cells grown in 6-well plates were harvested and centrifuged at $48 \mathrm{~h}$ after transfection. Cells were counted and washed twice with pre-cooled PBS. Then, cells were fixed and permeabilized overnight by adding $1 \mathrm{ml}$ of $70 \%$ pre-cooled ethanol to each tube at $4^{\circ} \mathrm{C}$. After centrifugation, the fixatives were decanted and cells were resuspended in $0.5 \mathrm{ml}$ of staining solution containing $50 \mu \mathrm{g} / \mathrm{ml} \mathrm{PI}$ and $100 \mu \mathrm{g} / \mathrm{ml}$ DNase-free RNase (Sigma-Aldrich) followed by $30 \mathrm{~min}$ of incubation at room temperature in the dark. Finally, cells were analyzed immediately by flow cytometry on a FACScan $^{\mathrm{TM}}$ system using CellQuest ${ }^{\mathrm{TM}}$ software (version 3.3) (BD Biosciences, San Jose, CA, USA).

$H \& E$ staining and immunohistochemistry. Tumor specimens were fixed in $10 \%$ formalin, paraffin-embedded, and cut into $4-\mu \mathrm{m}$ thick sections. The slides were dewaxed, and stained routinely with hematoxylin-eosin for histological assessments.

For immunohistochemistry, tumor tissue blocks were fixed in formalin, cut into $5-\mu \mathrm{m}$-thick sections, stained with $\mathrm{H} \& \mathrm{E}$, and processed for routine histological examination. For immunohistochemistry, slices were dewaxed; endogenous peroxidase activity was quenched by incubation in methanol containing $3 \%$ hydrogen peroxide for $10 \mathrm{~min}$. The sections were immunostained with rabbit anti-mouse MMP-2 and MMP-9 polyclonal antibodies (Santa Cruz Biotechnology Inc., USA). As a negative control, rabbit immunoglobulins (Vector Laboratories, Burlingame, CA, USA) were used to replace the primary antibodies. Goat anti-rabbit IgG conju- gated with horseradish peroxidase was used as secondary antibody. Immunohistochemical staining was performed at room temperature using the avidin-biotin-peroxidase complex method (Vectastain Elite ABC kit; Vector Laboratories).

Western blot analysis. Cell lysis, protein quantification and western blot assays were performed as previously described (20). The protein bands were visualized by SuperSignal West Pico Chemiluminescent Substrate (Pierce, Rockford, IL, USA), and membranes were subjected to X-ray autoradiography. Band intensities were determined with the Quantity One software (Bio-Rad). Experiments were performed in triplicate, and data are mean $\pm \mathrm{SE}$.

Statistical analysis. Data are mean \pm SE from three independent experiments. Statistical analyses were performed with SPSS17.0; the different groups were compared by one-factor analysis of variance (ANOVA). $\mathrm{P}<0.05$ was considered statistically significant.

\section{Results}

Atrazine promotes RMI cell proliferation. To explore the effect of atrazine on RM1 cell growth, MTT and colony formation assays were employed in vitro. MTT data showed significantly increased cell viability after treatment with 0.01 and $0.1 \mu \mathrm{M}$ atrazine compared with the control group, in a dose-dependent manner (Fig. 1A). To further assess the effects of atrazine on cell division, the expression levels of factors related to cell proliferation were assessed. Western 

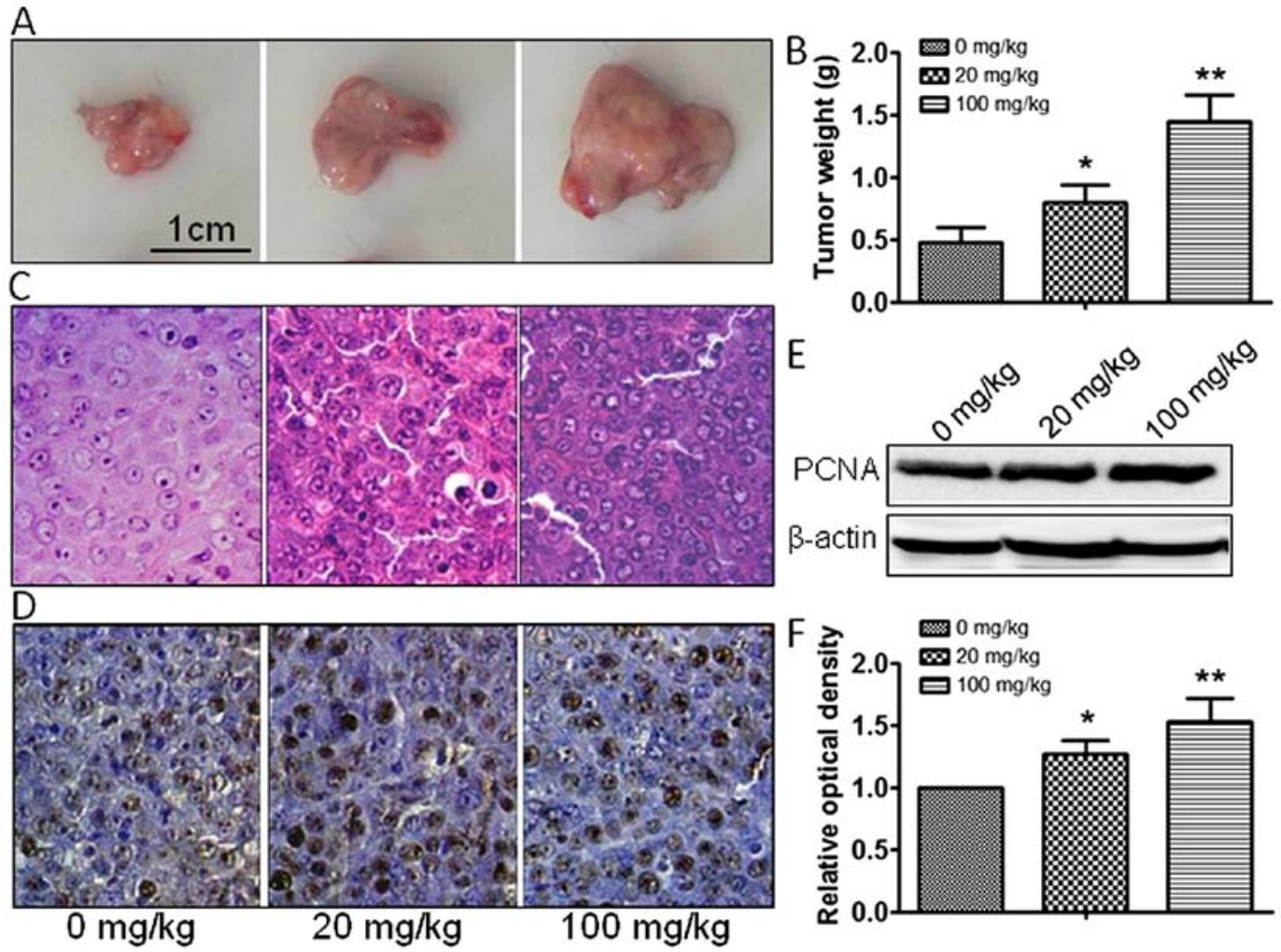

Figure 2. Atrazine promotes the proliferation of tumor cells in vivo. (A) Mice were treated with atrazine for 15 consecutive days; then, tumors were collected and the size and weight of the xenografts were measured. (B) Weight quantitation. (C) H\&E staining of tumor specimens. (D) PCNA was evaluated by immunohistochemical analysis. Specimens were scored and estimated in arbitrary units, ${ }^{* * *} \mathrm{P}<0.01$. (E) Western blot analysis of PCNA protein levels. (F) PCNA protein levels from three independent experiments. Columns, mean; bars, $\mathrm{SE}\left({ }^{* *} \mathrm{P}<0.01\right.$ versus control).
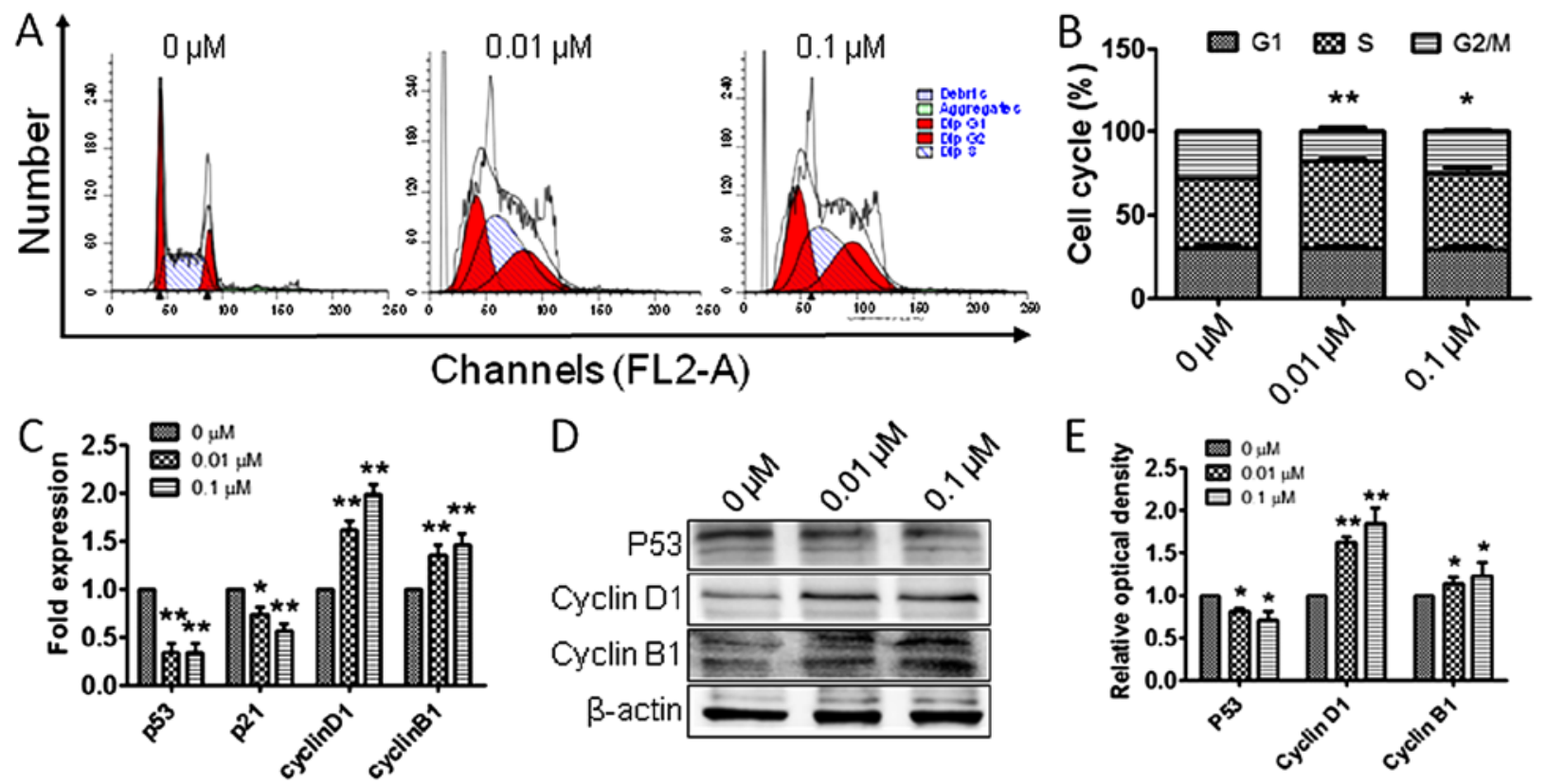

Figure 3. Atrazine accelerates the cell cycle in vitro. (A) PI staining and flow cytometry analysis. (B) Flow cytometry analysis comparing cell numbers between control and atrazine treated cells over a period of $48 \mathrm{~h}$. Mean \pm SEM of three independent experiments are presented. (C) qRT-PCR analysis of p53, p21, cyclin D1 and cyclin B1 mRNA levels, "* P<0.01. (D) Western blot analysis of P53, Cyclin D1 and Cyclin B1 protein amounts. (E) The P53, Cyclin D1 and Cyclin B1 protein levels from three independent experiments. Columns, mean; bars, $\mathrm{SE}\left({ }^{*} \mathrm{P}<0.05,{ }^{* *} \mathrm{P}<0.01\right.$ versus control).

blotting and immunocytochemistry were used to evaluate the expression of PCNA in vivo and in vitro. Compared with the control group, PCNA expression was dose-dependently higher after treatment with 0.01 and $0.1 \mu \mathrm{M}$ atrazine (Fig. 1B-D). Colony formation assay results showed significantly enhanced proliferation ability of cells in the 0.01 and $0.1 \mu \mathrm{M}$ atrazine 

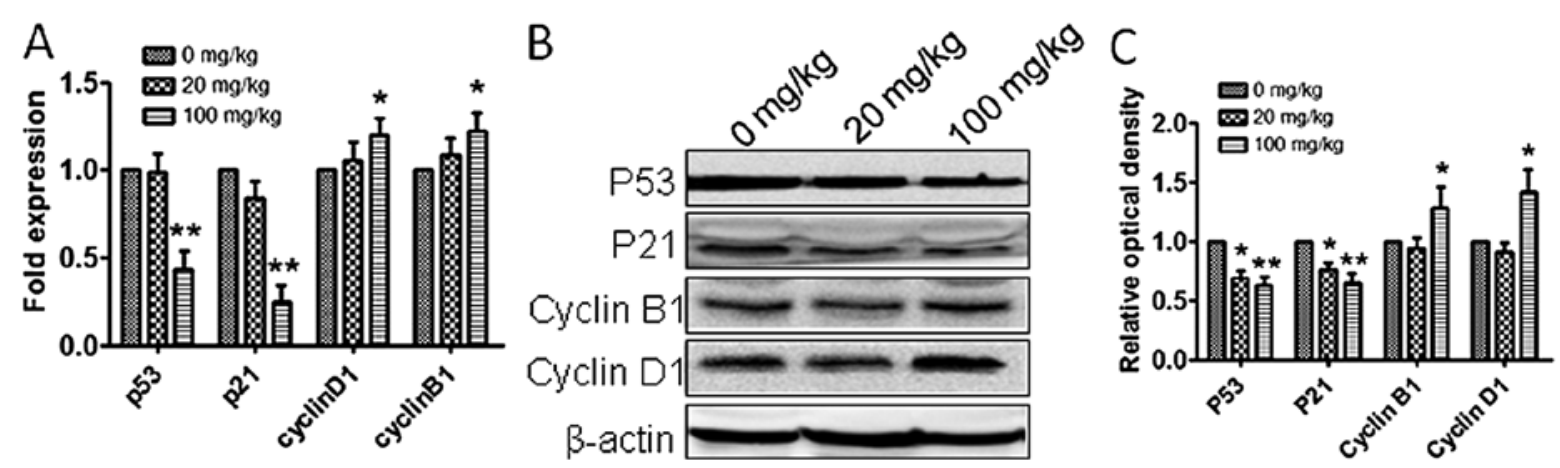

Figure 4. Atrazine accelerates the cell cycle in vivo. (A) qRT-PCR analysis of p53, p21, cyclin D1 and cyclin B1 mRNA expression. (B) Western blot analysis of P53, P21, Cyclin D1 and Cyclin B1 protein amounts. (C) Quantitation of P53, P21, Cyclin D1 and Cyclin B1 protein levels from three independent experiments. Columns, mean; bars, $\mathrm{SE}\left({ }^{*} \mathrm{P}<0.05,{ }^{* *} \mathrm{P}<0.01\right.$ versus control).
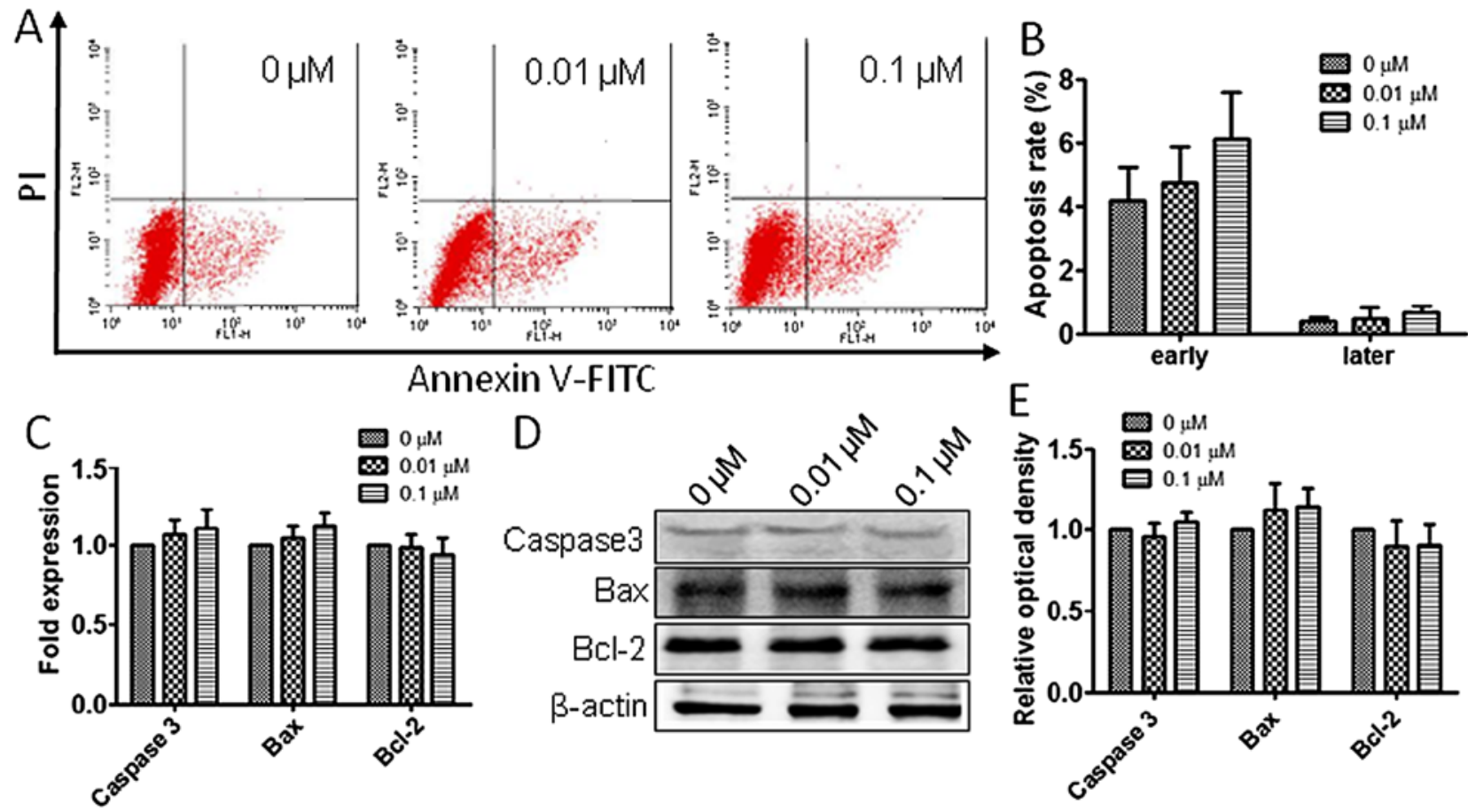

Figure 5. Impact of atrazine on apoptosis in RM1 cells in vitro. (A and B) After treatment, RM1 cells were stained with Annexin V/PI and analyzed by flow cytometry. (C) qRT-PCR analysis of the quantity of Bax, Bcl-2 and Caspase-3 mRNA. (D) Western blot analysis for Bax, Bcl-2 and Caspase-3 protein. (E) Bax, Bcl-2 and Caspase-3 protein levels from three independent experiments. Columns, mean; bars, $\mathrm{SE}\left({ }^{* *} \mathrm{P}<0.01\right.$ versus control).

groups, compared with the control group (Fig. 1E and 1F). In vivo, tumor size and weight were measured, and atrazine was found to accelerate the growth of tumor cells in a dosedependent manner (Fig. 2A-C). In addition, PCNA expression was dose-dependently increased by 20 and $100 \mathrm{mg} / \mathrm{kg}$ atrazine (Fig. 2D-F). Taken together, these data indicated that atrazine promoted RM1 cell proliferation. Together, these data suggested that atrazine promoted RM1 cell proliferation.

Atrazine accelerates cell cycle progression in RM1 cells. To explore whether the observed proliferation of RM1 cells is related to cell cycle alterations, flow cytometry was employed to detect the cell populations in the G1, S and G2 phases. Interestingly, RM1 cells in G2 phase were significantly increased after treatment with 0.01 and $0.1 \mu \mathrm{M}$ atrazine, respectively, compared with the control group (Fig. 3A and B), indicating that atrazine may promote RM1 cell proliferation by increasing the $\mathrm{G} 2$ population. To determine the molecular mechanisms by which atrazine increases cells in G2 phase, RT-PCR and western blot analyses were employed to assess the expression levels of $\mathrm{p} 53$, cyclin $\mathrm{B} 1$ and cyclin $\mathrm{D} 1$, in vitro and in vivo. The expression of $\mathrm{p} 53$ was downregulated and cyclin B1 and cyclin D1 amounts were upregulated (Figs. 3C-E and 4), which suggested that atrazine can accelerate the cell cycle by helping RM1 cells go through the G1-S and G2-M checkpoints.

Atrazine has no remarkable impact on apoptosis in RMI cells. To assess the atrazine effects on RM1 cell apoptosis, flow cytometry analysis was employed as described above. As shown in Fig. 5A and B, apoptosis rates in the three groups showed no statistically significant difference, suggesting that 

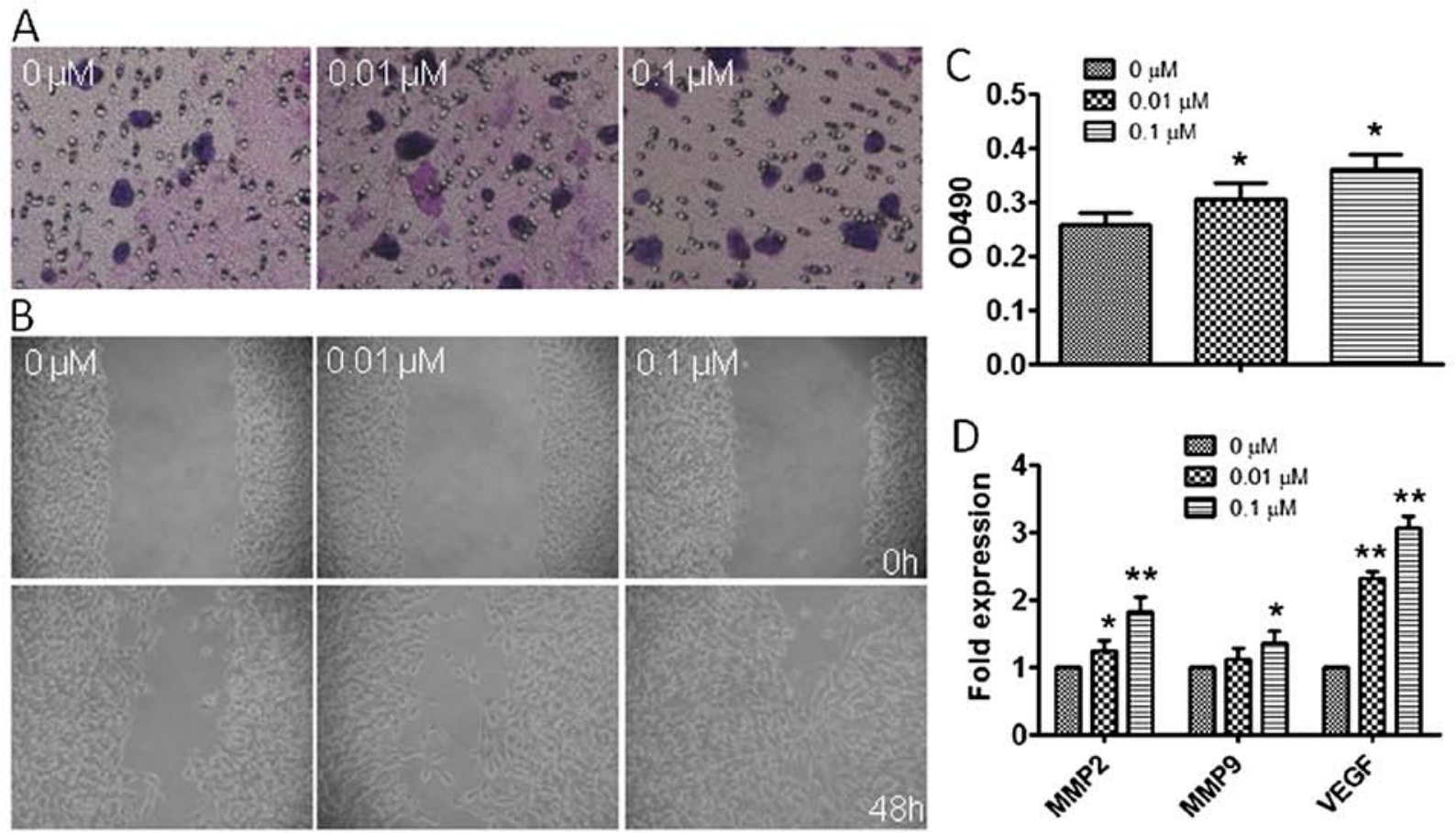

Figure 6. Atrazine induces cell migration, cell invasion and the expression of the matrix metalloproteinases MMP-2 and MMP-9. (A) Invasion of cells through a basement membrane (Matrigel) was detected in Transwell chamber assays. (B) Migration ability was determined by wound healing assays. (C) Data represent the number of migrated cells relative to untreated controls, and expressed as mean $\pm \mathrm{SE}$ from triplicate experiments ("P $<0.05$ versus control). (D) qRT-PCR analysis of MMP2, MMP9 and VEGF mRNA amounts. Columns, mean; bars, $\mathrm{SE}\left({ }^{*} \mathrm{P}<0.05,{ }^{* * *} \mathrm{P}<0.01\right.$ versus control).
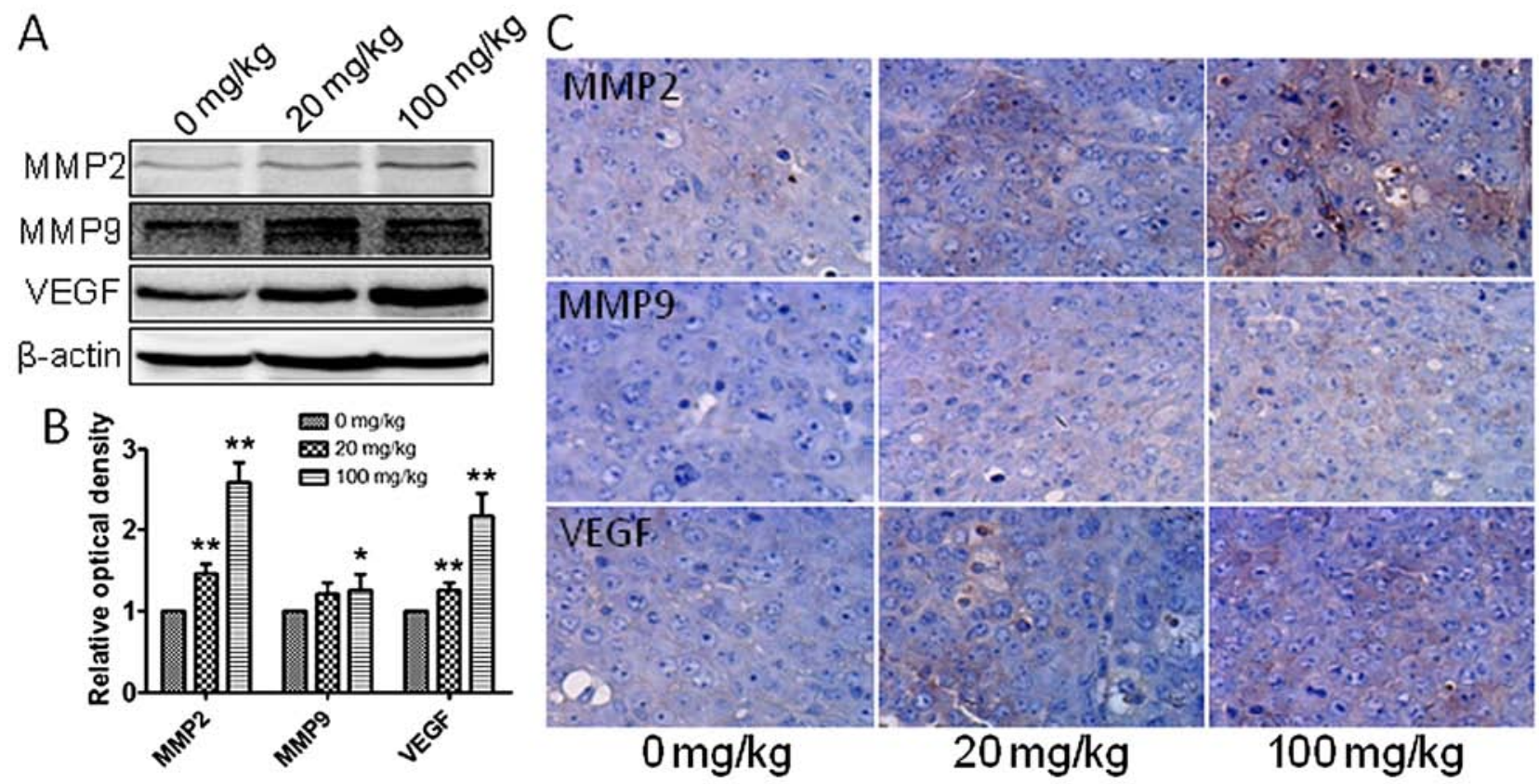

Figure 7. Atrazine induces migration and invasion of RM1 cells in vivo. (A) Western blot analysis of MMP2, MMP9 and VEGF protein amounts. (B) Quantitation of MMP2, MMP9 and VEGF protein levels from three independent experiments. Columns, mean; bars, $\mathrm{SE}\left({ }^{*} \mathrm{P}<0.05,{ }^{* *} \mathrm{P}<0.01\right.$ versus control). (C) MMP2, MMP9 and VEGF levels were evaluated by immunohistochemical analysis. Specimens were scored and estimated in arbitrary units.

atrazine has no significant impact on apoptosis in RM1 cells. Also, RT-PCR and western blot analyses were employed to evaluate the mRNA and protein levels of Caspase-3, Bax and Bcl-2 in vitro, and no significant differences among groups treated by different concentrations of atrazine and controls were obtained (Fig. 5C-E).
Atrazine enhances invasion and migration in RM1 cells. To explore the effects of atrazine on migration and invasion in RM1 cells, wound healing and transwell migration assays were employed. Interestingly, migration of cells in the 0.01 and $0.1 \mu \mathrm{M}$ atrazine groups were significantly enhanced compared to controls in wound closure (Fig. 6A); in addition, 

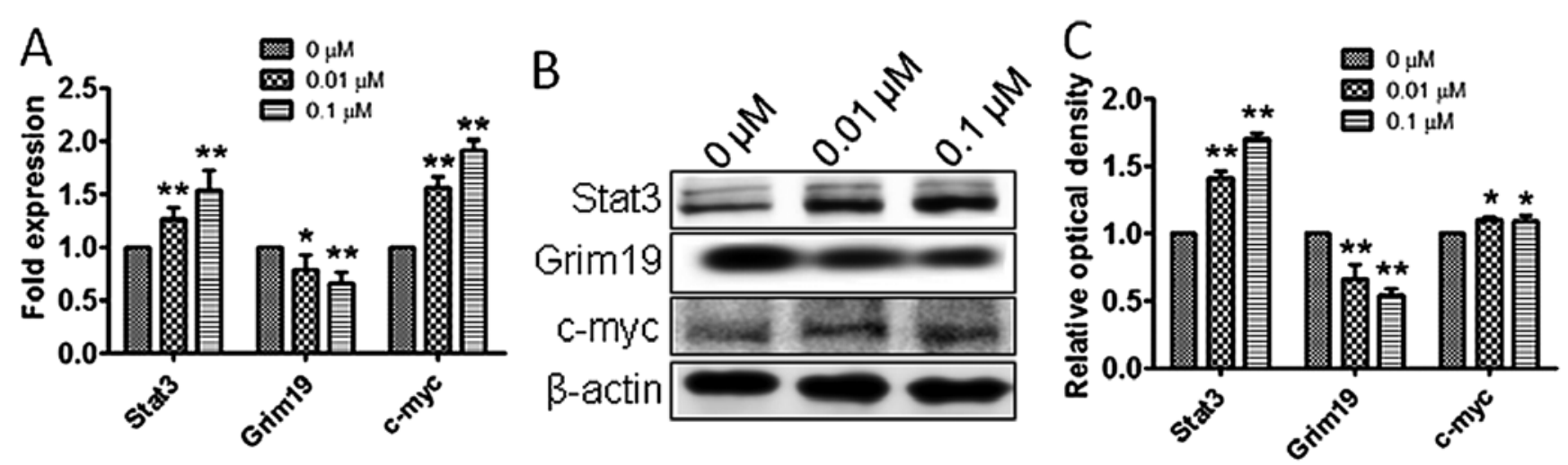

Figure 8. Atrazine activates the STAT3 signaling pathway in vitro. (A) qRT-PCR analysis of Grim-19, Stat3 and c-myc mRNA levels. (B) Western blot analysis of Grim-19, Stat3 and c-myc protein amounts. (C) Quantitation of Grim-19, Stat3 and c-myc protein levels from three independent experiments. Columns, mean; bars, $\mathrm{SE}\left({ }^{*} \mathrm{P}<0.05,{ }^{* *} \mathrm{P}<0.01\right.$ versus control).

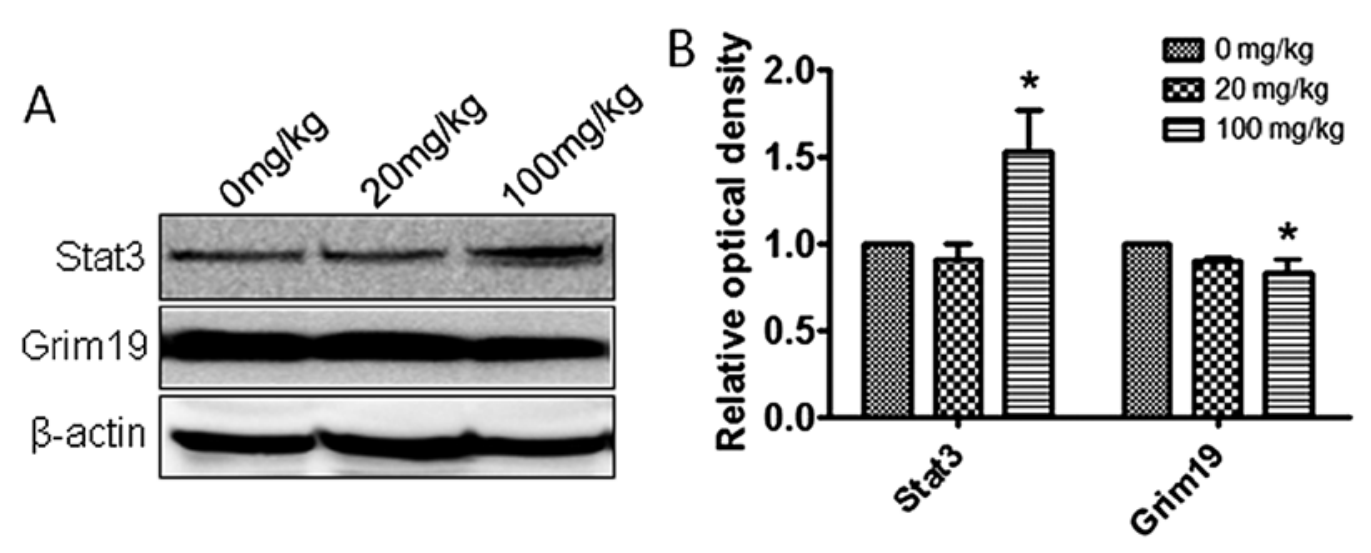

Figure 9. Atrazine activates the Stat3 signaling pathway in vivo. (A) Western blot analysis of Grim-19 and Stat3 protein amounts. (B) Quantitation of Grim-19 and Stat 3 protein levels from three independent experiments. Columns, mean; bars, $\mathrm{SE}\left({ }^{*} \mathrm{P}<0.05\right.$ versus control).

the number of invasive cells exposed to atrazine were remarkably increased compared with values obtained for the control group, especially at high dose (Fig. 6B and C). Moreover, western blotting, qRT-PCR and immunohistochemistry were employed to assess the in vivo expression of MMP2, MMP9 and VEGF, which are related to tumor migration and invasion. Gene and protein levels of MMP2, MMP9 and VEGF were significantly increased after exposure to atrazine in a dose-dependent manner (Figs. 6D and 7), indicating starkly enhanced migration and invasion abilities. This indicated that atrazine can enhance invasion and migration ability of RM1 cells.

Atrazine activates the STAT3 signaling pathway. To explore the molecular mechanisms by which atrazine promotes proliferation, accelerates cell cycle, and enhances cell migration and invasion abilities, qRT-PCR and western blotting were employed to detect the expression levels of Stat3, c-myc and Grim-19 in vitro and in vivo. Interestingly, mRNA and protein levels of Stat 3 and c-myc were higher and Grim-19 lower in the 0.01 and $0.1 \mu \mathrm{M}$ atrazine groups, compared with the control group, in a dose-dependent manner (Figs. 8 and 9), suggesting that atrazine may activate STAT3 signaling to enhance proliferation, migration and invasion in RM1 cells.

\section{Discussion}

Atrazine, a pesticide widely used to control broadleaf weeds in agriculture worldwide and especially in America, has been detected frequently in surface and ground water, where it tends to persist for months (21). This alarms medical researchers and environmentalists. Studies have reported that atrazine affects the endocrine and reproductive systems; however, whether it impacts the growth of tumor cells remains unclear. Prostate cancer is the most common malignancy in men, and epidemiologists have reported that pesticides can cause prostate cancer. Here, we used the RM1 cell line to explore the contribution of atrazine to the development of prostate cancer.

In this study, MTT and colony formation assays were employed in vitro to demonstrate that atrazine promoted RM1 cell proliferation.

PCNA is a known molecular marker for cell proliferation, and a regulator of the essential cellular function of cell growth. Upregulated expression of PCNA indicates the enhanced proliferation ability of cells (22). Western blotting and immunohistochemistry data obtained both in vitro and in vivo showed that PCNA levels were higher after exposure to atrazine, which suggested that atrazine can enhance RM1 cell proliferation. 
Increased cell proliferation indicates induced mitosis and/ or inhibited apoptosis. To assess how atrazine promotes RM1 cell proliferation, flow cytometry was employed to detect the changes in cell cycle distribution and apoptosis of RM1 cells in vitro; interestingly, the rates of G2 phase cells were increased, while apoptosis rates were unchanged after exposure to atrazine, which suggested that atrazine promotes mitosis by accelerating the cell cycle, but has no significant impact on apoptosis. To further clarify the molecular mechanisms by which atrazine affects cell cycle and apoptosis in RM1 cells, RT-PCR and western blot analyses were employed to detect the mRNA and protein levels of factors related to cell cycle and apoptosis. The cell cycle has many checkpoints, and p53 and p21 play important roles in cell cycle arrest through the Chk2-p53-Cdc25A-p21-MCM4 signaling pathway, and finally induce G1 cell cycle arrest; overexpression of p21 induces cell cycle arrest (23). In this study, p53 and p21 mRNA and protein levels were downregulated in vitro and in vivo after exposure to atrazine, which indicated that atrazine inhibits cell cycle arrest. Cyclin B1 (G2/mitotic-specific, cyclin B1; CCNB1) is essential for cell cycle control at the G2/M transition, and interacts with the CDK1 protein kinase to form a serine/threonine kinase holoenzyme complex also known as MPF; cyclin D1 binds and activates Cdk4 to regulate G1 $\rightarrow \mathrm{S}$ phase transition $(24,25)$. In this study, cyclin B1 and cyclin D1 were upregulated after atrazine treatment, which suggested that atrazine can help RM1 cells go through the G2-M and G1-S checkpoints. Gene and protein levels of factors related to apoptosis, such as Bax, Bcl-2 and Caspase-3, were also detected by RT-PCR and western blot analyses: no significant differences were noted after treatment with atrazine (26-28).

It is well known that tumor migration and invasion are the main factors that promote cancer progression. To assess whether atrazine effects RM1 cell migration and invasion in mouse prostate cancer, in vitro invasion and wound-healing assays were employed. As shown above, migration and invasion abilities of RM1 cells were enhanced after treatment with atrazine. To clarify the underlying molecular mechanisms, RT-PCR and western blot analyses were employed to assess mRNA and protein amounts of a series of genes, including MMP2, MMP9 and VEGF. It is known that VEGF is crucial for vascular development and neovascularization in physiological and pathological cancer progression (29). In addition, VEGF is essential for cell migration (30). MMP2 and MMP9 are frequently highly expressed in various malignant tumors and appear to increase with development stages; indeed, these proteins are essential for cancer invasion and metastasis. Li et al reported that MMP2 and MMP9 upregulation promotes the migration and invasion of tumor cells (31). In this study, VEGF, MMP2 and MMP9 were upregulated by atrazine in vitro and in vivo, indicating that atrazine can promote metastasis and migration in RM1 cells.

It is well known that proto-oncogene and anti-oncogene unbalance induces tumor occurrence and development. RT-PCR and western blot analyses were employed to assess mRNA and protein levels of STAT3, Grim-19 and c-myc in vitro and in vivo. Grim-19 participates in multiple pathways affecting cell growth as a tumor suppressor; therefore, its deregulation is advantageous to cancer development (32). STAT3, an oncogene essential for tumor growth (33), is constitutively active in a number of human cancers, affecting autocrine growth factors. Activated STAT3 induces the expression of a number of cellular proto-oncogenes, including c-myc, c-fos and c-met, as well as cell cycle regulating proteins such as cyclin D1 and cyclin B1, which are all known to promote tumor growth. Grim-19 directly interacts with STAT3, inhibiting its gene function through Grim-19-depentment inhibitory and stimulatory pathways $(34,35)$. In this study, STAT3 and c-myc were upregulated, and Grim-19 downregulated, indicating that atrazine may upregulate STAT3 by downregulating Grim-19, promoting RM1 cell proliferation.

This study hinted that atrazine may activate the STAT3 signaling pathway by reducing the production of ROS, which induce the cell pro-oncogene c-myc as well as cell cycle regulators such as cyclin D1 and cyclin B1. Upregulation of c-myc, cyclin B1 and cyclin D1 accelerates the cell cycle, promoting the proliferation of tumor cells. Moreover, VEGF, MMP1 and MMP9 upregulation enhances the migration and invasion of tumor cells. These effects promote tumor malignancy. Therefore, prostate cancer patients should stay away from atrazine, and farmers should be regularly screened for prostate cancer.

\section{References}

1. Dong X, Zhu L, Wang J, Wang J, Xie H, Hou X and Jia W: Effects of atrazine on cytochrome P450 enzymes of zebrafish (Danio rerio). Chemosphere 77: 404-412, 2009.

2. Lin Z, Fisher JW, Ross MK and Filipov NM: A physiologically based pharmacokinetic model for atrazine and its main metabolites in the adult male C57BL/6 mouse. Toxicol Appl Pharmacol 251: 16-31, 2011.

3. Gerecke AC,Schärer M,SingerHP, MüllerSR,Schwarzenbach RP, Sägesser M, Ochsenbein U and Popow G: Sources of pesticides in surface waters in Switzerland: Pesticide load through waste water treatment plants - current situation and reduction potential. Chemosphere 48: 307-315, 2002.

4. Ren J, Jiang K and Zhou H: The concentration and source of atrazine residue in water of Guanting reservoir. Huan Jing $\mathrm{Ke}$ Xue 23: 126-128, 2002 (In Chinese).

5. Na T, Fang Z, Zhanqi G, Ming Z and Cheng S: The status of pesticide residues in the drinking water sources in Meiliangwan Bay, Taihu Lake of China. Environ Monit Assess 123: 351-370, 2006.

6. Rodriguez VM, Thiruchelvam M and Cory-Slechta DA: Sustained exposure to the widely used herbicide atrazine: Altered function and loss of neurons in brain monoamine systems. Environ Health Perspect 113: 708-715, 2005.

7. Coban A and Filipov NM: Dopaminergic toxicity associated with oral exposure to the herbicide atrazine in juvenile male C57BL/6 mice. J Neurochem 100: 1177-1187, 2007.

8. Cooper RL, Stoker TE, Tyrey L, Goldman JM and McElroy WK: Atrazine disrupts the hypothalamic control of pituitary-ovarian function. Toxicol Sci 53: 297-307, 2000.

9. Xing H, Wang C, Wu H, Chen D, Li S and Xu S: Effects of atrazine and chlorpyrifos on DNA methylation in the brain and gonad of the common carp. Comp Biochem Physiol C Toxicol Pharmacol 168: 11-19, 2015.

10. Zhang X, Wang M, Gao S, Ren R, Zheng J and Zhang Y: Atrazineinduced apoptosis of splenocytes in BALB/C mice. BMC Med 9: $117,2011$.

11. Boffetta P, Adami HO, Berry SC and Mandel JS: Atrazine and cancer: A review of the epidemiologic evidence. Eur J Cancer Prev 22: 169-180, 2013.

12. Van Leeuwen JA, Waltner-Toews D, Abernathy T, Smit B and Shoukri M: Associations between stomach cancer incidence and drinking water contamination with atrazine and nitrate in Ontario (Canada) agroecosystems, 1987-1991. Int J Epidemiol 28: 836-840, 1999.

13. Kandori H, Suzuki S, Asamoto M, Murasaki T, Mingxi T, Ogawa $\mathrm{K}$ and Shirai T: Influence of atrazine administration and reduction of calorie intake on prostate carcinogenesis in probasin/ SV40 T antigen transgenic rats. Cancer Sci 96: 221-226, 2005. 
14. Fan W, Yanase T, Morinaga H, Gondo S, Okabe T, Nomura M, Komatsu T, Morohashi K, Hayes TB, Takayanagi R, et al: Atrazine-induced aromatase expression is SF-1 dependent: Implications for endocrine disruption in wildlife and reproductive cancers in humans. Environ Health Perspect 115: 720-727, 2007.

15. Wang G, Niu X, Zhang W, Caldwell JT, Edwards H, Chen W, Taub JW, Zhao L and Ge Y: Synergistic antitumor interactions between MK-1775 and panobinostat in preclinical models of pancreatic cancer. Cancer Lett 356B: 656-668, 2015.

16. Zhang Y, Hao H, Zhao S, Liu Q, Yuan Q, Ni S, Wang F, Liu S, Wang L and Hao A: Downregulation of GRIM-19 promotes growth and migration of human glioma cells. Cancer Sci 102: 1991-1999, 2011.

17. Hao H, Liu J, Liu G, Guan D, Yang Y, Zhang X, Cao X and Liu Q Depletion of GRIM-19 accelerates hepatocellular carcinoma invasion via inducing EMT and loss of contact inhibition. J Cell Physiol 227: 1212-1219, 2012.

18. Nallar SC, Kalakonda S, Sun P, Ohmori Y, Hiroi M, Mori K, Lindner DJ and Kalvakolanu DV: Identification of a structural motif in the tumor-suppressive protein GRIM-19 required for its antitumor activity. Am J Pathol 177: 896-907, 2010.

19. Huang Y, Yang M, Yang H and Zeng Z: Upregulation of the GRIM-19 gene suppresses invasion and metastasis of human gastric cancer SGC-7901 cell line. Exp Cell Res 316: 2061-2070, 2010.

20. Zhang L, Gao L, Li Y, Lin G, Shao Y, Ji K, Yu H, Hu J, Kalvakolanu DV, Kopecko DJ, et al: Effects of plasmid-based Stat3-specific short hairpin RNA and GRIM-19 on PC-3M tumor cell growth. Clin Cancer Res 14: 559-568, 2008.

21. Graymore M, Stagnitti $F$ and Allinson G: Impacts of atrazine in aquatic ecosystems. Environ Int 26: 483-495, 2001.

22. Wang SC: PCNA: A silent housekeeper or a potential therapeutic target? Trends Pharmacol Sci 35: 178-186, 2014.

23. Yun HJ, Hyun SK, Park JH, Kim BW and Kwon HJ: Widdro activates DNA damage checkpoint through the signaling Chk2p53-Cdc25A-p21-MCM4 pathway in HT29 cells. Mol Cell Biochem 363: 281-289, 2012.

24. Schick V, Majores M, Fassunke J, Engels G, Simon M, Elger CE and Becker AJ: Mutational and expression analysis of CDK1, cyclin A2 and cyclinB1 in epilepsy-associated glioneuronal lesions. Neuropathol Appl Neurobiol 33: 152-162, 2007.
25. Lee Y, Dominy JE, Choi YJ, Jurczak M, Tolliday N, Camporez JP, Chim H, Lim JH, Ruan HB, Yang X, et al: Cyclin D1-Cdk4 controls glucose metabolism independently of cell cycle progression. Nature 510: 547-551, 2014.

26. Lamb HM and Hardwick JM: Unlatched BAX pairs for death. Cell 152: 383-384, 2013

27. Volkmann N, Marassi FM, Newmeyer DD and Hanein D: The rheostat in the membrane: BCL-2 family proteins and apoptosis. Cell Death Differ 21: 206-215, 2014.

28. Li SQ, Hu ZH, Zhu S, Wang DM, Han HM and Lu HJ: The effect of ADAM8 on the proliferation and apoptosis of hepatocytes and hepatoma carcinoma cells. J Biochem Mol Toxicol 29: 440-448, 2015.

29. Baka S, Clamp AR and Jayson GC: A review of the latest clinical compounds to inhibit VEGF in pathological angiogenesis. Expert Opin Ther Targets 10: 867-876, 2006.

30. Cross MJ, Dixelius J, Matsumoto T and Claesson-Welsh L: VEGFreceptor signal transduction. Trends Biochem Sci 28: 488-494, 2003.

31. Li G, Zhang Y, Qian Y,Zhang H, Guo S, Sunagawa M, Hisamitsu T and Liu Y: Interleukin-17A promotes rheumatoid arthritis synoviocytes migration and invasion under hypoxia by increasing MMP2 and MMP9 expression through NF- $\mathrm{B} / \mathrm{HIF}-1 \alpha$ pathway. Mol Immunol 53: 227-236, 2013.

32. Kalvakolanu DV, Nallar SC and Kalakonda S: Cytokine-induced tumor suppressors: A GRIM story. Cytokine 52: 128-142, 2010.

33. Moreira S, Correia M, Soares P and Máximo V: GRIM-19 function in cancer development. Mitochondrion 11: 693-699, 2011.

34. Liu YB, Zhang L, Guo YX, Gao LF, Liu XC, Zhao LJ, Guo BF, Zhao LJ, Zhao XJ and Xu DQ: Plasmid-based Survivin shRNA and GRIM-19 carried by attenuated Salmonella suppresses tumor cell growth. Asian J Androl 14: 536-545, 2012.

35. Zhou T, Chao L, Rong G, Wang C, Ma R and Wang X: Downregulation of GRIM-19 is associated with STAT3 overexpression in breast carcinomas. Hum Pathol 44: 1773-1779, 2013. 